\title{
Rancang Bangun Game Labirin Menggunakan Algoritma A Star Berbasis Mobile
}

\author{
Nur Budi Nugraha \\ Program Studi Informatika, Sekolah Tinggi Teknologi Dumai \\ Jl. Utama Karya Bukit Batrem II \\ Email: nurbudinugroho87@gmail.com
}

\begin{abstract}
ABSTRAK
Game adalah sebuah permainan dengan tujuan bersenang-senang dan mengisi waktu luang. Dalam perkembangannya game yang dulu dimainkan di halaman rumah bersama teman-teman sekitar lingkungan, dan kini semakin berkurang dengan berkembangnya teknologi dan permainan-permainan tradisional sudah berganti dengan permainan-permainan modern. Salah satu permainan klasik yang hingga saat ini masih sangat digemari adalah labirin. Labirin biasanya berawal dari sebuah jalur yang merupakan jalur buntu, dan hanya satu jalur yang merupakan jalan keluar, namun untuk membuat menarik, labirin dapat dibuat berujung banyak atau memiliki banyak jalan keluar sehingga misi penyelesaian masalah bertambah yang semula hanya satu jalan keluar menjadi banyak, terlebih lagi bila ada beberapa musuh yang menghalangi jalan keluar. Perancangan game labirin dengan menggunakan algoritma $A$ Star ini dilakukan melalui tahap-tahap berikut: 1) tahap pengumpulan data, 2) tahap analisa dan perancangan, 3) implementasi dan evaluasi game. Hasil dari penelitian ini adalah game labirin terdiri dari 3 stage, dimana pada masing-masing stage mempunyai tingkat kesulitan yang berbeda-beda sehingga dapat mengasah kecerdasan pemain dalam menyelesaikan misi setiap stagenya.
\end{abstract}

Kata kunci: Game, Stage, Labirin

\begin{abstract}
Game is a game with the aim of having fun and free time. In its development, games that were previously played on the home page with friends around the environment, and are now diminishing with the development of technology and games - traditional games have changed with modern games. One classic game that is still very popular today is the labyrinth. The labyrinth usually starts from a lane which is a dead end, and only one lane is a way out, but to make it interesting, the labyrinth can be made to a lot or has a lot of way out so that the problem solving mission increases only one exit becomes a lot, especially again if there are some enemies that block the exit. The design of the labyrinth game using the A Star algorithm is carried out through the following stages: 1) the data collection phase, 2) the analysis and design stage, 3) the implementation and evaluation of the game. The results of this study are maze games
\end{abstract}

UNITEX Vol 11 No.2 Juli - Desember 2018 | p-ISSN 2089-3957 | e-ISSN 2580-2585 
consisting of 3 stages, where each stage has different levels of difficulty so that it can hone the player's intelligence in completing each team's mission.

Keywords: Game, Stage, Maze

\section{Pendahuluan}

Dunia bermain sudah tidak lagi harus diluar ruangan. Manusia menciptakan permainan bukan hanya sebagai penghilang rasa bosan, tetapi banyak hal bisa dijadikan alasan untuk mengawali sebuah permaian, termasuk untuk belajar. Belajar dengan permainan merupakan metode yang cukup bagus digunakan karena tidak membuat pelajar menjadi cepat jenuh, sehingga semangat belajar selalu ada (wicaksono, 2016). Perkembangan dunia teknologi memungkinkan penempatan permainan didalam sebuah perangkat android. Karena telepon genggam android bukan hanya berguna sebagai alat komunikasi untuk melakukan panggilan telepon atau pengiriman pesan singkat saja, akan tetapi juga sebagai sarana yang dapat digunakan untuk menghilangkan kejenuhan dengan menanamkan aplikasi permainan di dalamnya (Rahadian, 2016).

Game adalah sebuah permainan dengan tujuan bersenang-senang dan mengisi waktu luang (sudarmilah 2016), Dalam perkembangannya game yang dulu dimainkan di halaman rumah bersama teman-teman sekitar lingkungan, dan kini semakin berkurang dengan berkembangnya teknologi dan permainan-pemainan tradisional sudah berganti dengan permainan-permainan modern. Permainan video adalah permainan yang mengunakan interaksi dengan antar muka pengguna melalui gambar yang dihasilkan oleh piranti video, pada umumnya permainan ini mempunyai tujuan atau gol (Putra, 2012). Salah satu permainan klasik yang hingga saat ini masih sangat digemari adalah labirin.

Labirin merupakan salah satu permasalahan yang cukup terkenal dalam sejarah kehidupan manusia, pada zaman dahulu, banyak kerajaan yang menggunakan model labirin untuk strategi pertahanan istana, menyembunyikan tempat rahasia, jalur pelarian dan lain-lain (Pribadi, 2012). Dan labirin pada masa kini lebih sering dinikmati sebagai sebuah permainan pemecahan masalah. Labirin biasanya berawal dari sebuah jalur yang merupakan jalur buntu, dan hanya satu jalur yang merupakan jalan keluar, namun untuk membuat menarik, labirin dapat dibuat berujung banyak atau memiliki banyak jalan keluar sehingga misi penyelesaian masalah bertambah yang semula hanya satu jalan keluar menjadi banyak, terlebih lagi bila ada beberapa musuh yang menghalangi jalan keluar.

UNITEX Vol 11 No.2 Juli - Desember 2018 | p-ISSN 2089-3957 | e-ISSN 2580-2585 


\section{Metode Penelitian}

Perancangan game labirin dengan menggunakan algoritma A Star ini dilakukan melalui tahap-tahap berikut: 1) tahap pengumpulan data, 2) tahap analisa dan perancangan, 3) implementasi dan evaluasi game.

1. Tahap Pengumpulan data

Pada tahap ini dilakukan pengumpulan data yang akan digunakan sebagai sumber dalam pembuatan game labirin. Pengumpulan data ini meliputi studi pustaka, mencari buku acuan atau jurnal yang berhubungan dengan game labirin.

2. Tahap analisa dan perancangan

Tahap kedua merupakan tahap analisa dan perancangan. Dimana pada tahap ini perancangan dibuat melalui bantuan UML yang meliputi usecase diagram, class diagram, statechart diagram serta perancangan interface yang akan digunakan dalam game ini. Game ini terdiri dari 3 stage, dimana masing masing stage memiliki tingkat kesulitan yang berbeda-beda.

3. Implementasi dan evaluasi game

Tahap akhir dilakukan implementasi dan evaluasi apakah game yang telah dibuat dapat berjalan dengan baik. Hasil perancangan UML tersebut diimplementasikan kedalam program android studio dengan menggunakan bahasa java. Setelah selesai diimplementasi, game labirin diuji dan evaluasi untuk dilakukan pengembangan atau perbaikan apabila dalam game masih ditemukan kesalahan (error).

\section{Hasil dan Pembahasan}

Rancangan game labirin menggunakan usecase digaram. Usecase digaram berguna untuk mendeskripsikan fungsi fungsi dari sebuah sistem dari sudut pandang pengguna (aktor) dengan sistemnya sendiri. Dimana yang ditekankan dalam usecase diagram ini adalah apa yang dilakukan, bukan bagaiamana melakukannya. 


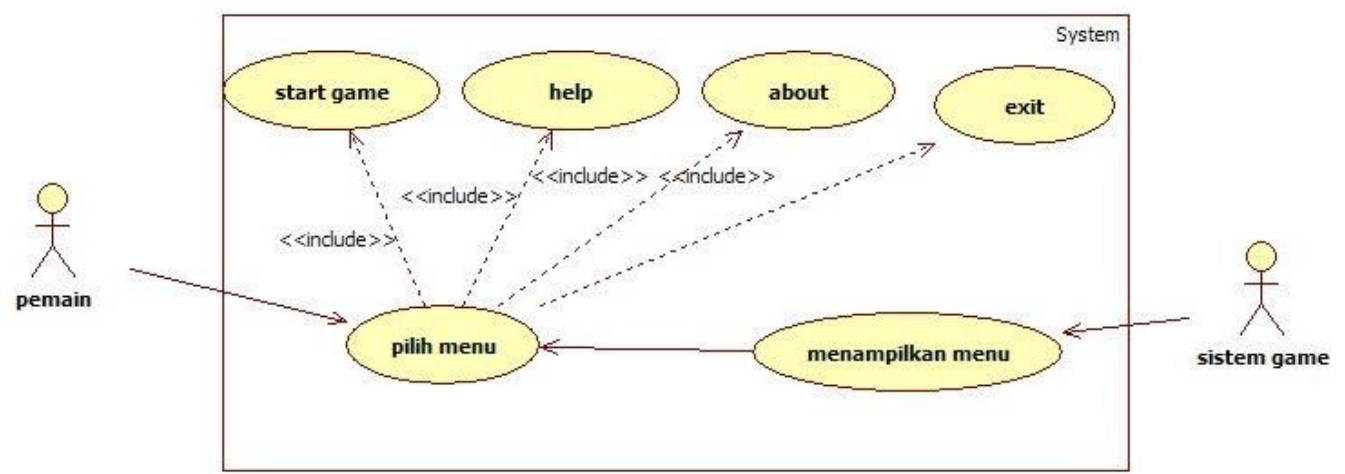

Gambar 1. Usecase diagram game labirin

Skenario pada Usecase Diagram diatas menjelaskan tentang bagaimana pemain memulai permainan labirin ini. Diawali dari pemain memilih menu yang ditampilkan oleh sistem game. Menu awal yang ditampilkan oleh sistem game adalah Start, About, Help, dan Exit. Apabila pemain memeilih menu Help maka sistem game akan menampilkan penjelasan mengenai spesifikasi game labirin ini. Apabila pemain memilih menu About maka sistem game akan menampilkan data author game. Apabila pemain ingin keluar dari game ini maka dapat memilih menu Exit. Dan untuk dapat memainkan game maka pemain harus memilih menu Start. Pada saat pemain memilih menu Start maka sistem akan menampilkan permainan Stage1, pada pemainan ini pemain ditugaskan untuk mencari kunci agar dapat membuka pintu, pemain harus membuka kunci secara berurutan agar dapat melanjutkan ke Stage berikutnya. Pemain harus waspada terhadap musuh laba-laba yang berkeliaran, apabila pemain terkena musuh maka permainan akan berakhir. 


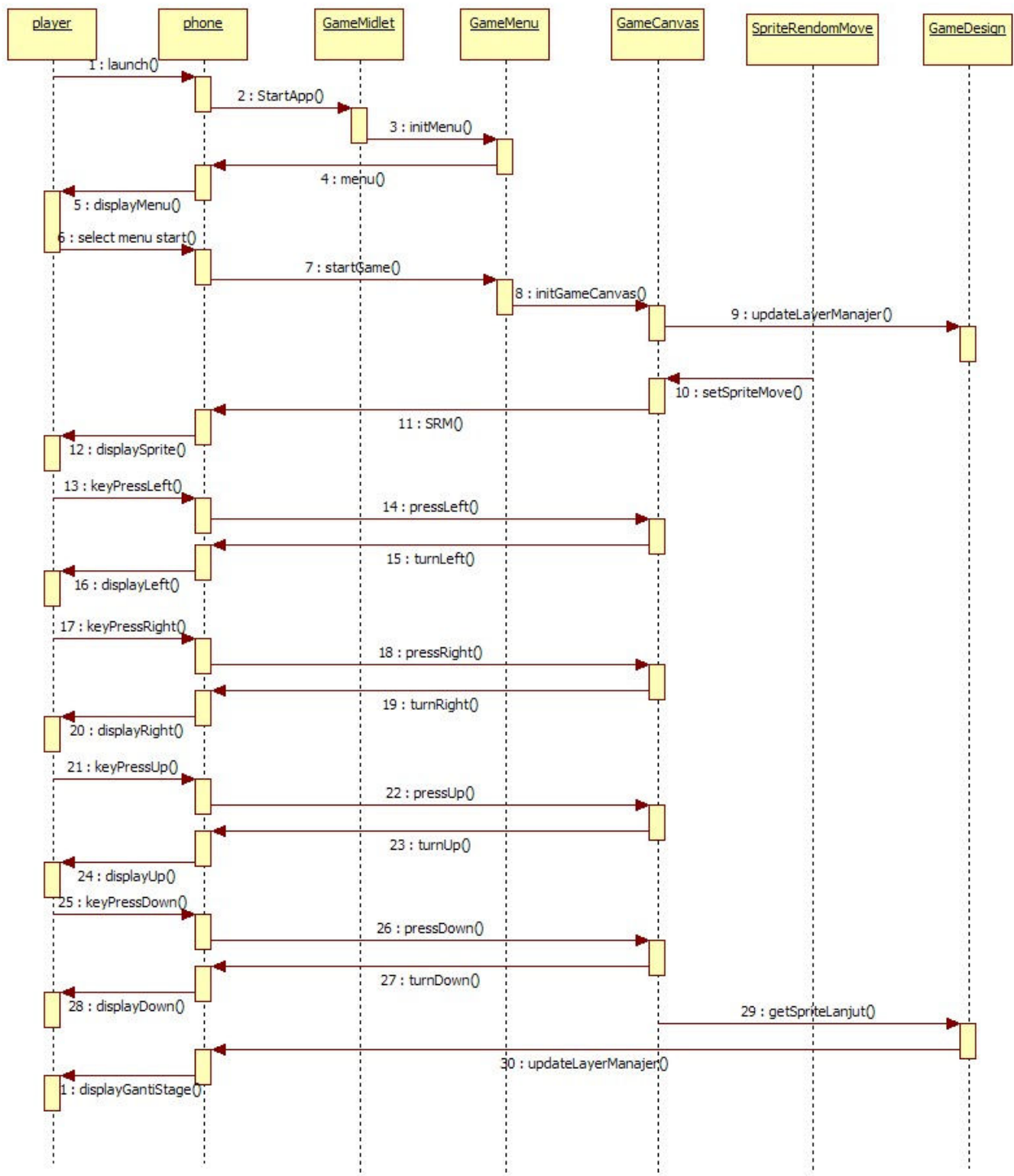

Gambar 2. Sequence diagram game labirin

Sequence Diagram pada Gambar 2 menggambarkan urutan kerja ketika memainkan game. Semakin kebawah maka waktu yang dibutuhkan maka semakin lama. Ketika pemain menjalankan game maka class yang dipanggil adalah class GameMidlet, yang kemudian class GameMidlet memanggil Class Game Menu yang 
akan ditampilkan pada layar Ponsel. Saat pemain memilih menu "Start Game" maka akan memanggil class GameCanvas. Class GameCanvas akan menanggil class GameDesign yang menangani semua image yang berkaitan dengan game. Didalam class GameCanvas menangani event yang berkaitan dengan pengaturan arah/gerak dari player, jika player menekan tombol atas (up) maka class GameCanvas akan memanggil syntax ((keyState \& UP_PRESSED) !=0) dan akan menampilkan gerak sprite pindah keatas. Jika player menekan tombol bawah (down) maka class GameCanvas akan memanggil syntax ((keyState \& DOWN_PRESSED) != 0) dan akan menampilkan gerak sprite pindah kebawah. Jika player menekan tombol kanan (right) maka class GameCanvas akan memanggil syntax ((keyState \& RIGHT_PRESSED) != 0) dan akan menampilkan gerak sprite pindah kekanan. Jika player menekan tombol kiri (left) maka class GameCanvas akan memanggil syntax ((keyState \& LEFT_PRESSED) != 0) dan akan menampilkan gerak sprite pindah kekiri. Jika player telah menelesaikan satu Stage maka ia dapat lanjut ke Stage berikutnya. 

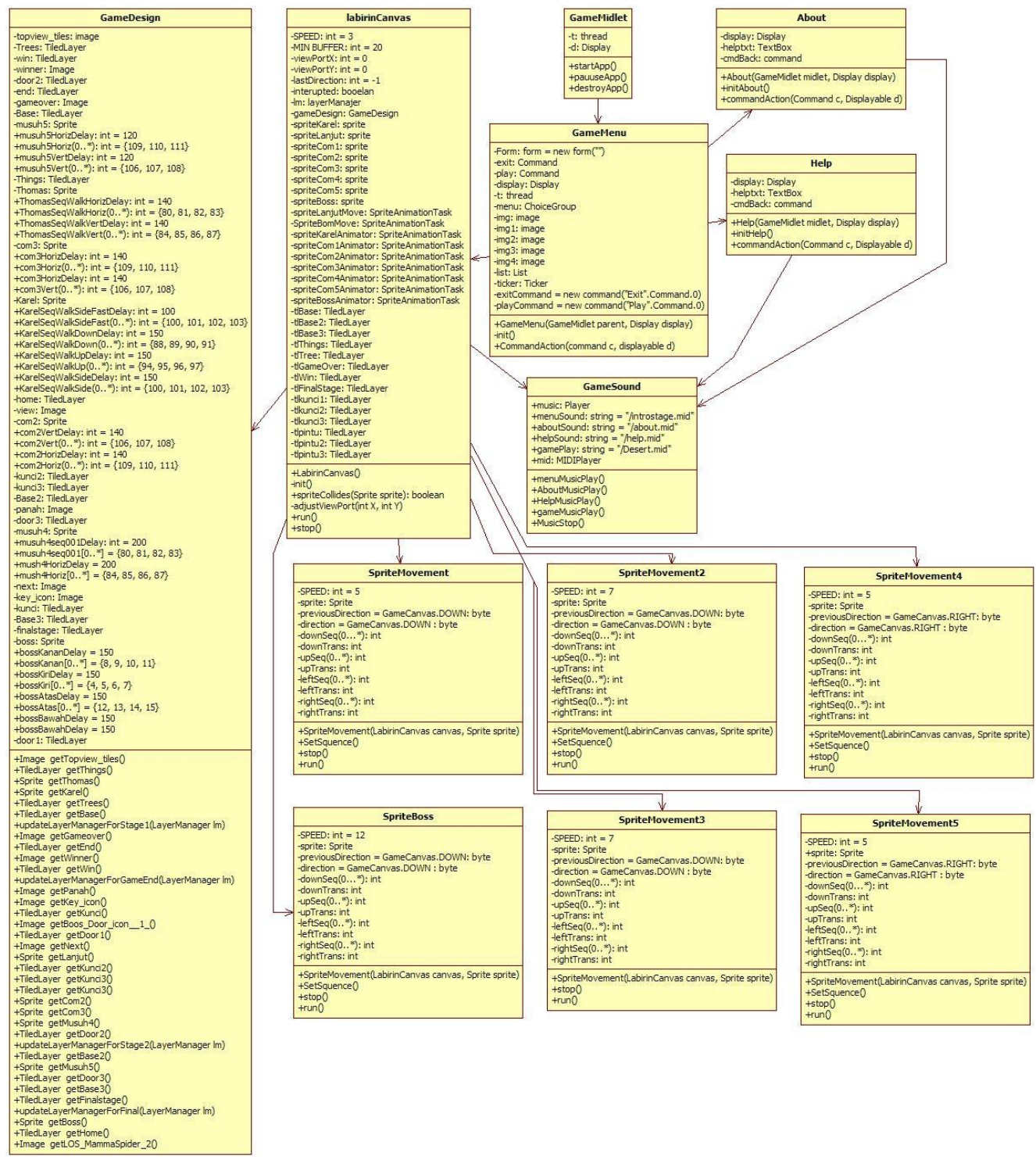

Gambar 3. Class diagram game labirin

Class Diagram pada Gambar 3 menggambarkan hubungan yang terjadi antar class yang terkait dengan Game Labirin yang dibuat. Class GameMidlet merupakan class utama didalam sistem game labirin ini, karena class GameMidlet ini merupakan class yang pertama kali dipanggil pada saat menjalankan aplikasi. Pada saat aplikasi dijalankan pada perangkat handphone maka class GameMidlet akan 
memanggil method startApp (), pada method startApp() dilakukan pemanggilan class GameMenu untuk menampilkan menu game ke layar handphone, selanjutnya class GameMenu akan melakukan pemanggilan class-class yang diperlukan dalam proses berjalannya aplikasi. Class GameMenu akan melakukan pemanggilan terhadap class-class berikut:

1. Class Labirin Canvas

Class ini dijalankan pada saat pemain memilih menu "Start". Class ini digunakan untuk menjalankan semua method yang digunakan untuk game labirin ini. Class Labirin canvas ini juga memanggil class lain yaitu:

a. Class GameDesignClass GameDesign merupakan class yang digunakan untuk mendesign karakter, musuh, serta stage didalam game labirin ini.

b. Class SpriteRandomMovement

Class SpriteRandomMovement ini digunakan untuk menggerakkan karakter musuh.

c. Class SpriteRandomMovement2

Class SpriteRandomMovement2 ini digunakan untuk menggerakkan karakter musuh2.

d. Class SpriteRandomMovement3

Class SpriteRandomMovement3 ini digunakan untuk menggerakkan karakter musuh3.

e. Class SpriteRandomMovement4

Class SpriteRandomMovement4 ini digunakan untuk menggerakkan karakter musuh4

f. Class SpriteRandomMovement5

Class SpriteRandomMovement5 ini digunakan untuk menggerakkan karakter musuh5.

g. Class SpriteBoss

Class SpriteBoss ini digunakan untuk menggerakkan karakter Boss.

h. Class GameSound

Class ini digunakan untuk menampilkan background musik pada saat game dimainkan

2. Class About

Class ini digunakan untuk menampilkan informasi mengenai data pembuat game. Class ini juga memanggil 1 class yaitu: Class GameSoundClass ini digunakan untuk menampilkan background musik pada saat pemain memilih menu About.

3. Class Help

UNITEX Vol 11 No.2 Juli - Desember 2018 | p-ISSN 2089-3957 | e-ISSN 2580-2585 
Class ini berisi spesifikasi dari game labirin ini. Apabila pemain memilih menu Help maka sistem akan menampilkan isi dari class Help. Class ini juga memanggil 1 class yaitu Class GameSound yaitu Class ini digunakan untuk menampilkan background musik pada saat pemain memilih menu Help.

User Interface

Pada saat aplikasi dijalankan maka class yang pertama kali dipanggil adalah class GameMidlet. Class GameMidler akan memanggil method:

public void startApp() \{

$d=$ Display.getDisplay(this);

menu = new GameMenu(midlet, $d)$;

d.setCurrent(gameCanvas);

\}

Method tersebut merupakan method untuk menampilkan Main Menu.

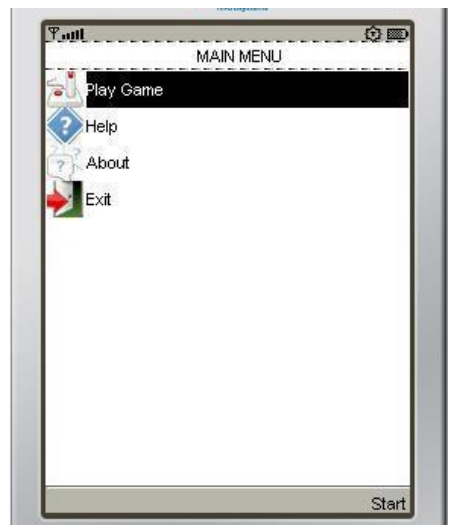

Gambar 4. Tampilan menu game

Pada saat pemain memilih menu "Play Game" maka class GameMenu akan memanggil method:

gameCanvas = new LabirinCanvas();

$t=$ new Thread(gameCanvas);

t.start();

display = Display.getDisplay(parent);

display.setCurrent(gameCanvas);

gameCanvas.addCommand(ExitCommand);

gameCanvas.setCommandListener(this);

UNITEX Vol 11 No.2 Juli - Desember 2018

| p-ISSN 2089-3957 | e-ISSN 2580-2585 


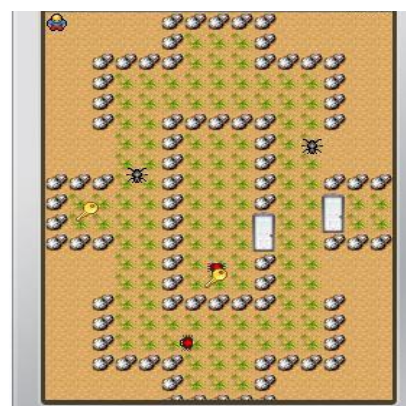

Gambar 5. Tampilan stage 1

Untuk menampilkan objek-objek pada Stage1 maka pada class LabirinCanvas akan menginisialisasi objek-objek tersebut melalui method:

$$
\begin{aligned}
& \text { this.tlkunci = this.gameDesign.getKunci(); } \\
& \text { this.tlpintu = this.gameDesign.getDoor1(); } \\
& \text { this.tlkunci2 = this.gameDesign.getKunci2(); } \\
& \text { this.tlpintu2 = this.gameDesign.getDoor2(); } \\
& \text { this.tlkunci3 = this.gameDesign.getKunci3(); } \\
& \text { this.tlpintu } 3=\text { this.gameDesign.getDoor3(); } \\
& \text { this.tlTrees = this.gameDesign.getTrees(); } \\
& \text { this.tlBase = this.gameDesign.getBase(); } \\
& \text { this.lm = new LayerManager(); } \\
& \text { gameDesign.updateLayerManagerForStage1(lm); }
\end{aligned}
$$

Apabila sprite membentur objek/dinding maka class LabirinCanvas akan memanggil method:

Sprite.collidesWith(

this.tlTrees, true)

|| sprite.collidesWith(this.tlpintu2, true)

| | sprite.collidesWith(this.tlpintu3, true)

| | sprite.collidesWith(this.tlThings, true)

|| sprite.collidesWith(this.tlFinalStage, true)

| | sprite.get $X()<0||$ sprite.get $Y()<0$

| | sprite.get $X()>($ this.tlBase.getWidth() - sprite.getWidth())

| | sprite.get $Y()>($ this.tlBase.getHeight() - sprite.getHeight()

);

Apabila sprite Karel berhasil mencapai tujuan (spriteLanjut) maka akan memanggil method:

this.lm = new LayerManager();

UNITEX Vol 11 No.2 Juli - Desember 2018 | p-ISSN 2089-3957 | e-ISSN 2580-2585 
gameDesign.updateLayerManagerForStage2(lm); this.tlBase2 = this.gameDesign.getBase2();

Ketika memainkan game labirin maka state awal dimulai dari pemanggilan method StartApp() dari class GameMidlet selanjutnya proses inisialisasi menu yang dijalankan pada class GameMenu. Apabila dipilih menu Exit, maka aplikasi akan ditutup. Kemudian apabila dipilih menu Start, class GameMenu akan melakukan action GameThread Stage1 untuk menampilkan permainan Stage1.

Program utama akan melakukan inisialisasi terhadap objek musik untuk menampilkan background suara pada permainan, dan inisialisai objek GameDesign Stage1 untuk menampilkan gambar-gambar yang diperlukan selama permainan berjalan. Ketika terjadi proses penekanan tombol arah atas pada handphone, maka class utama (class LabirinCanvas) akan melakukan action untuk menginisialisasi perubahan frame dari sprite Karel untuk bergerak/berjalan keatas/naik. Kemudian apabila terjadi proses penekanan tombol arah bawah pada handphone, maka class utama (class LabirinCanvas) akan melakukan action untuk menginisialisasi perubahan frame dari sprite Karel untuk bergerak/berjalan turun.

Apabila terjadi proses penekanan tombol arah kanan pada handphone, maka class utama (class LabirinCanvas) akan melakukan action untuk menginisialisasi perubahan frame dari sprite Karel untuk bergerak/berjalan kekanan. Apabila terjadi proses penekanan tombol arah kiri pada handphone, maka class utama (class LabirinCanvas) akan melakukan action untuk menginisialisasi perubahan frame dari sprite Karel untuk bergerak/berjalan kekiri. Apabila sprite Karel menabrak objek maka class utama akan memanggil method spriteCollides yang akan menginisialisasi jika terjadi benturan, jika sprite Karel membentur objek pohon atau batu maka sprite akan berhenti, jika sprite Karel membentur sprite musuh maka akan ditampilkan GameOver, dan apabila sprite Karel berhasil mencapai tujuan, maka class utama akan menampilkan Stage selanjutnya.

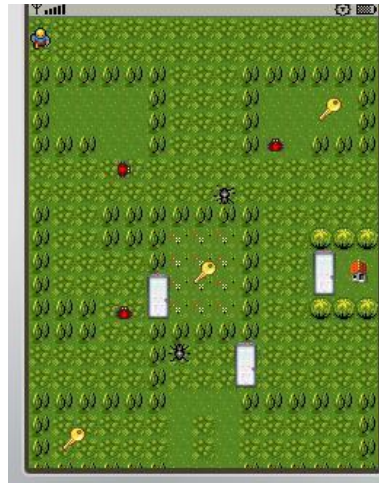

Gambar 6. Tampilan stage 2

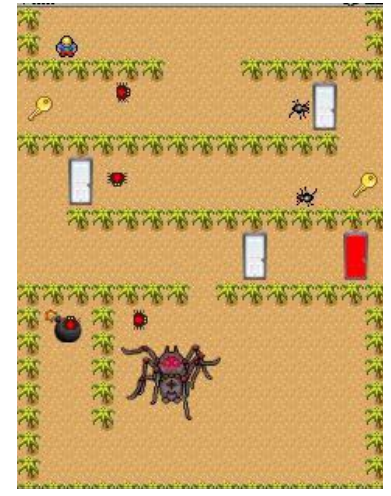

Gambar 7. Tampilan stage 3

UNITEX Vol 11 No.2 Juli - Desember 2018 | p-ISSN 2089-3957 | e-ISSN 2580-2585 
Apabila sprite Karel mengenai musuh maka class LabirinCanvas akan memanggil method:

this.lm = new LayerManager();

gameDesign.updateLayerManagerForGameEnd(lm);

this.tlGameOver = gameDesign.getEnd();

music.MusicStop();

Kemudian akan menampilkan "Game Over" pada layar handphone.

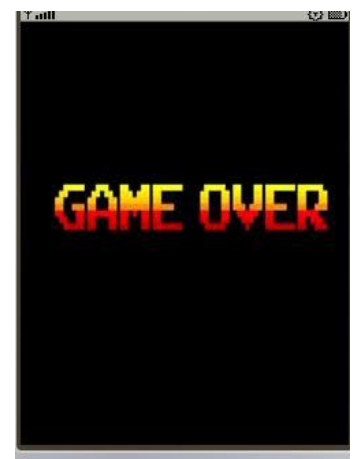

Gambar 8. Tampilan layar kalah

Jika pemain berhasil menyelesaikan stage terakhir maka class GameCanvas akan memanggil method:

this.lm = new LayerManager();

gameDesign.updateLayerManagerForGameWin(lm);

this.tlWin= gameDesign.getWin();

music.MusicStop();

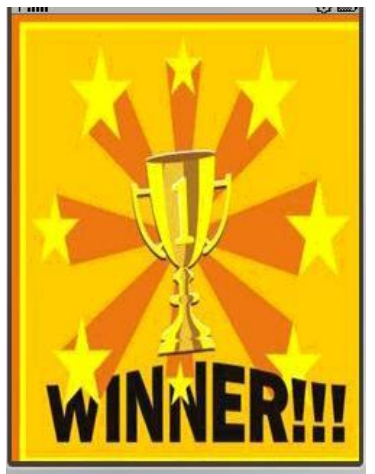

Gambar 9. Tampilan layar menang

UNITEX Vol 11 No.2 Juli - Desember 2018 | p-ISSN 2089-3957 | e-ISSN 2580-2585 


\section{Pengujian}

Di bawah ini merupakan pengujian aplikasi algoritma A* (A Star) untuk menguji perangkat lunak yang sudah dibangun sudah berjalan seperti yang diharapkan atau belum. Pengujian dilakukan berdasarkan algoritma A* (A Star) yang ada pada tombol bantuan stage 1 .

Perhitungan algoritma $A^{*}$ menggunakan euclidean heuristic yang digunakan untuk mencari jalur terpendek antara dua buah simpul horizontal dan vertikal. Nilai n.x, n.y $=0$ dan goal.x, goal.y $=1$ yang diambil dari jarak simpul pada game. Nilai node (grid) yaitu 20x26 pixel dimana 1 grid = 1 pixel ke arah horizontal atau 1 pixel ke arah vertical. Nilai $h(n)$ heuristic di dapat dari jarak perkiraan dari simpul awal ke simpul tujuan. Nilai f(n) didapat dari penjumlahan dari g(n) dan h(n).

$$
\begin{aligned}
& \text { Posisi simpul awal }=n . x: 0, n . y: 0 \\
& \text { Posisi simpul tujuan = Goal.x: 19, Goal. } y: 25 \\
& g(0,1)=1 \\
& h(n)=\sqrt{(n \cdot x-\text { goal. } x)^{2}+(n \cdot y-\text { goal. } y)^{2}} \\
& h(0,1)=\sqrt{(0-19)^{2}+(1-25)^{2}} \\
& h(0,1)=\sqrt{(-19)^{2}+(-24)^{2}} \\
& h(0,1)=\sqrt{361+576}=\sqrt{937} \\
& h(0,1)=30,61 \\
& f(n)=g(n)+h(n) \\
& f(0,1)=1+30,61=31,61
\end{aligned}
$$

Untuk mencari jalur terpendek dari stage 1 membutuhkan 156 langkah dengan simpul yang diperiksa yaitu 186 simpul, Dari hasil pengujian algoritma $\mathrm{A}^{*}(A$ star) yang dilakukan, dapat disimpulkan bahwa bantuan yang ada pada game petualangan labirin sudah berjalan menggunakan euclidean heuristic.

\section{Simpulan}

Setelah melakukan proses perancangan, pembangunan, dan pengujian aplikasi game labirin ini, diperoleh kesimpulan bahwa dengan adanya game labirin ini dapat menjadi hiburan dan mengasah kecerdasan dari pemainnya. Karena dalam game ini terdapat 3 stage dengan tingkat kesulitan yang berbeda sehingga dapat mengasah strategi dan pola pikir dari pemain ini. Selain itu game ini besar kecilnya ukuran dari aplikasi game yang dibuat sangat dipengaruhi oleh ukuran file gambar, file suara atau musik, dan banyaknya source code yang digunakan. Game yang berjalan lacar pada emulator belum tentu dapat berjalan dengan baik pada 
perangkat aslinya. Hal ini disebabkan keterbatasan yang dimiliki oleh handphone yang bersangkutan, baik dari segi memori dan spesifikasi sistem java dalam handphone tersebut.

\section{Daftar Pustaka}

Wicaksono, R. M., \& R Sandhika Galih Amalga, D. S., 2016. Pembuatan Game Petualangan Menggunaka Construct2 (Doctoral dissertation, Fakultas Teknik Unpas).

Rahadian, M., Agustri, S., \& Suhandi, N. 2016. Pembangunan Game Ayo Tarik Berbasis Android. Jurnal Informatika Global.

Sudarmilah, E., \& Wibowo, P.A., 2016. Aplikasi Augmented Reality Game Edukasi untuk Pengenalan Organ Tubuh Manusia Khazanah Informatika: Jurnal Ilmu Komputer dan Informatika, 2(1), 20-25.

Putra, R. D., Aswin, M., \& Djuriatno, W. 2012. Pencarian Rute Terdekat Pada Labirin Menggunakan Merode A*. Jurnal EECCIS, 6(2).

Pribadi, B. 2013. Pembangunan Game Edukasi Smart Labyrinth Berbasis Dekstop (Doctoral dissertation, Universitas Komputer Indonesia).

Jogiyanto HM, 2005. Analisis dan Disain Sistem Informasi, Yogyakarta: Andi Offset.

Lewis Moronta, 2003. Game Development with Action Script, Course Technology PTR.

M.Suyanto, 2007. Analisis \& Desain Aplikasi Multimedia Untuk Pemasaran, Yogyakarta: Andi Offset.

Wahana Komputer, 2008. Menguasai Adobe Photoshop CS3, Yogyakarta: Andi Offset. 